\title{
Programmable Assembly of DNA-Functionalized Liposomes by DNA
}

\author{
Neeshma Dave and Juewen Liu* \\ Department of Chemistry, Waterloo Institute for Nanotechnology, University Of Waterloo \\ Waterloo, Ontario, N2L 3G1, Canada \\ Email: liujw@uwaterloo.ca
}

Received: November 6, 2010

Accepted: December 16, 2010

Published Online: January 04, 2011

* To whom correspondence should be addressed. Phone: 519-888-4567 ext 38919. E-mail: liujw@uwaterloo.ca.

This document is the Accepted Manuscript version of a Published Work that appeared in final form in ACS Nano, copyright $\odot$ American Chemical Society after peer review and technical editing by publisher. To access the final edited and published work see http://dx.doi.org/10.1021/nn1030093 


\begin{abstract}
Bionanotechnology involves the use of biomolecules to control both the structure and property of nanomaterials. One of the most studied examples is DNA-directed assembly of inorganic nanoparticles such as gold nanoparticles (AuNPs). However, systematic studies on DNA-linked soft nanoparticles, such as liposomes, are still lacking. We herein report the programmable assembly and systematic characterization of DNA-linked liposomes as a function of liposome size, charge, fluidity, composition, DNA spacer, linker DNA sequence, and salt concentration for direct comparison to DNA-directed assembly of AuNPs. Similar to the assemblies of AuNPs, sharp melting transitions were observed for liposomes where the first derivative of the melting curve full width at half-maximum (fwhm) is equal to or less than $1{ }^{\circ} \mathrm{C}$ for all of the tested liposomes, allowing sequence specific DNA detection. We found that parameters such as liposome size, charge, and fluidity have little effect on the DNA melting temperature. Cryo-TEM studies showed that programmable assemblies can be obtained and that majority of the liposomes maintained a spherical shape in the assembled state. While liposome and AuNP systems are similar in many aspects, there are also important differences that can be explained by their respective physical properties.
\end{abstract}

\title{
Keywords: liposomes, DNA, nanoparticles, melting, assembly, cryo-TEM
}


One of the main goals of bionanotechnology is to use biomolecules to control both the structure and property of nanomaterials and in turn influence their biomolecular behavior. ${ }^{1-8}$ This interplay between bio- and nano-components is well illustrated in DNA-directed assembly of nanomaterials. ${ }^{1,2}$ DNA possesses a programmable structure that can be manipulated with sub-nanometer precision. In addition, its high stability and the availability of a wide range of attachment chemistry allow DNA to have an increasingly important role in nanotechnology. ${ }^{3,4,7,9,10}$ For example, DNA has been used to construct scaffolds with well-defined geometry and periodicity, upon which DNA-functionalized nanoparticles were immobilized to follow the underlying DNA pattern. ${ }^{4,8,11-13}$ In another approach, linker DNAs are used to assemble inorganic nanoparticle oligomers and polymers. ${ }^{1,2}$ Gold nanoparticles (AuNPs) are particularly attractive for these studies as DNA conjugation to Au surface can be achieved using simple Au-thiol chemistry. In addition, AuNP assembly is accompanied with a visible color change from red-to-blue popularizing them as colorimetric sensors. ${ }^{5,9,14,15}$ Furthermore, assembled AuNPs can be easily disassembled upon DNA melting resulting in a much sharper melting transition compared to free DNA, ${ }^{16}$ which is attributed to multivalent and cooperative DNA binding. ${ }^{17-}$ 19 DNA-directed assembly has also been studied using other inorganic nanoparticles such as silver nanoparticles, quantum dots, silica, and magnetic nanoparticles. ${ }^{5,9}$

While inorganic nanoparticles possess unique optical and magnetic properties, soft materials are highly biocompatible with excellent cargo loading and releasing properties. Liposomes are particularly attractive because of their well-established applications in drug delivery, ${ }^{20}$ templated materials synthesis, ${ }^{21-23}$ and analytical chemistry. ${ }^{24}$ These applications can be further expanded by covalent DNA attachment to allow encoding, patterning, ${ }^{25}$ targeted delivery, ${ }^{26}$ and programmable assembly. ${ }^{27}$ Compared to the vast amount of literature related to inorganic nanoparticles, DNA-directed assembly of liposomes has been studied only recently. ${ }^{25,27-40}$ For example, liposomes have been immobilized through DNA linkages to form 2-D patterns, control liposome lateral interactions, ${ }^{25,30,31}$ and detect 
DNA. ${ }^{41-43}$ Liposomes containing fusogenic lipids have been shown to fuse if they are brought close enough to one another via DNA hybridization. ${ }^{29,32,33,44}$ By using a dual-lipid modified DNA, nonfunctionalized liposomes can be assembled via spontaneous insertion of the lipid chains into the liposomes. $^{27,34}$ Liposome-to-micelle transition has also been realized via DNA hybridization. ${ }^{45}$ However, none of these studies showed programmability in terms of liposome composition, size, charge, or fluidity. More importantly, there is no direct comparison between soft and hard nanoparticles in DNA-directed assembly experiments.

From a pure physical science stand point, liposomes differ from inorganic nanoparticles in several important ways. First, liposomes are formed by self-assembled lipid molecules via non-covalent interactions. Therefore, liposomes can be easily deformed (so they are soft) while inorganic nanoparticles cannot be deformed by forces at the molecular level. Second, the physical property of liposomes can be manipulated by simply changing the lipid head group to be either positive, negative, or zwitterionic. The composition of the tails can also be tuned to influence the lipid phase transition temperature. Third, by changing lipid curvature and composition, fusion can be selectively promoted or avoided. ${ }^{29,33}$ Finally, with a fluid bilayer membrane, the attached DNAs are mobile and can re-organize on the membrane surface in response to external stimuli. For inorganic nanoparticles, however, the immobilized ligands cannot diffuse easily on the particle surface. Therefore, important insights can be obtained through a side-by-side comparison of these soft and hard nanoparticles. We report herein a three-component system with two DNA-functionalized liposomes and a linker DNA. Side-by-side comparisons to AuNPs have also been carried out. While there are many similarities between liposomes and AuNPs in terms of DNA-directed assembly, we also observed important differences that can be explained by their respective physical properties. 


\section{Results and Discussion}

System Design. Our system comprises of three components: two kinds of DNA-functionalized liposomes and a linker DNA (Figure 1A). Each component can be independently varied as long as the DNA linkages are maintained. For example, we varied the liposome by first changing its fluidity and secondly, by changing the head group charge. DOPC and DPPC possess no overall charge (Figure 1B), but the latter is non-fluid at room temperature. Fluid DOPG has an anionic head group. We did not include cationic lipids since they may aggregate in the presence of negatively charged DNA via electrostatic interactions, disallowing us to study DNA-directed assembly.

In a typical experiment, liposome aggregates were prepared using a concentration of 0.25 $\mathrm{mg} / \mathrm{mL}$ (each liposome) in the presence of $2.5 \mu \mathrm{M}$ linker DNA. As shown in the inset of Figure 2C, large gel-like DOPC liposome aggregates were formed; while in the absence of the linker DNA, the liposomes were well-dispersed. To help visualize liposomes, $1 \%$ rhodamine-B labeled lipid was included in this experiment to give a pink color. For all the other studies in this paper, no dye labels were used. The assembled liposome aggregates can be easily purified by centrifugation to remove free DNA and non-incorporated liposomes. For example, the supernatant is clear after purification (inset of Figure 2C), indicating that all the liposomes were in the aggregated form. Conversely, at temperatures above DNA melting, $\mathrm{T}_{\mathrm{m}}$, aggregated liposomes disassemble to produce a clear solution. As established for DNA-linked AuNPs, ${ }^{16,17,19}$ melting transition experiments can also provide rich information regarding liposome assembly. 


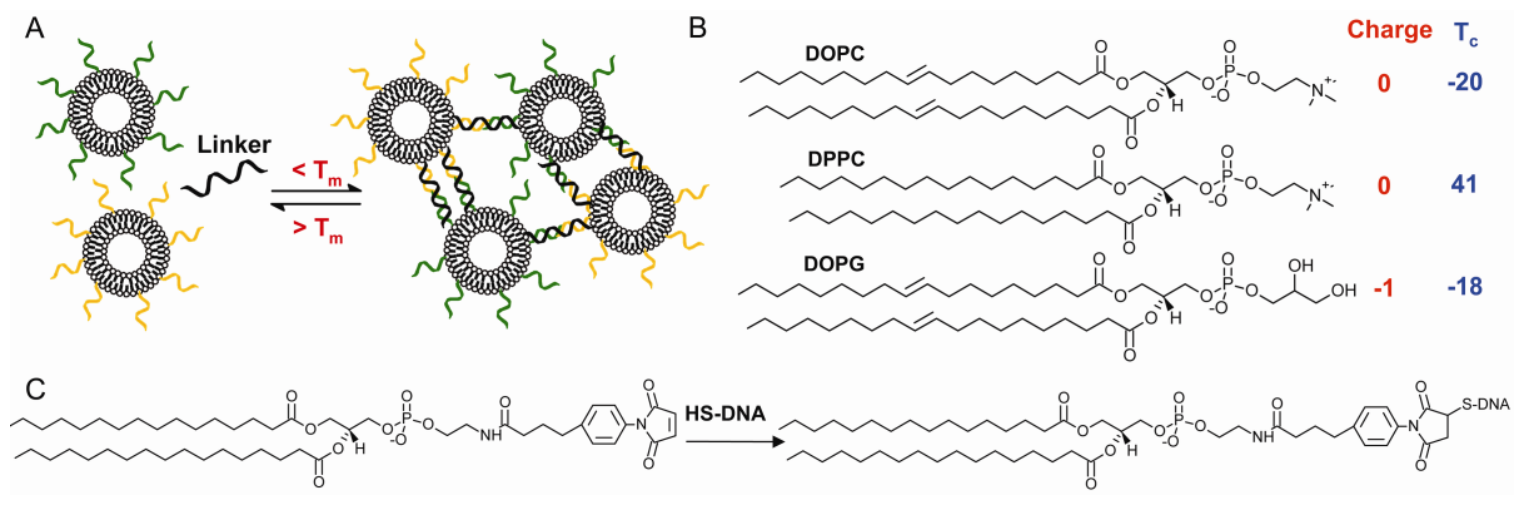

Figure 1. (A) DNA-directed assembly of DNA-functionalized liposomes where $T_{m}$ is the DNA melting temperature within the assembled liposomes. (B) The different phospholipids used in this study and their respective charge and lipid phase transition temperature $\left(\mathrm{T}_{\mathrm{c}}\right)$ values are also shown. $(\mathrm{C})$ The conjugation chemistry for covalent attachment of a thiol-modified DNA to a MPB-PE lipid.
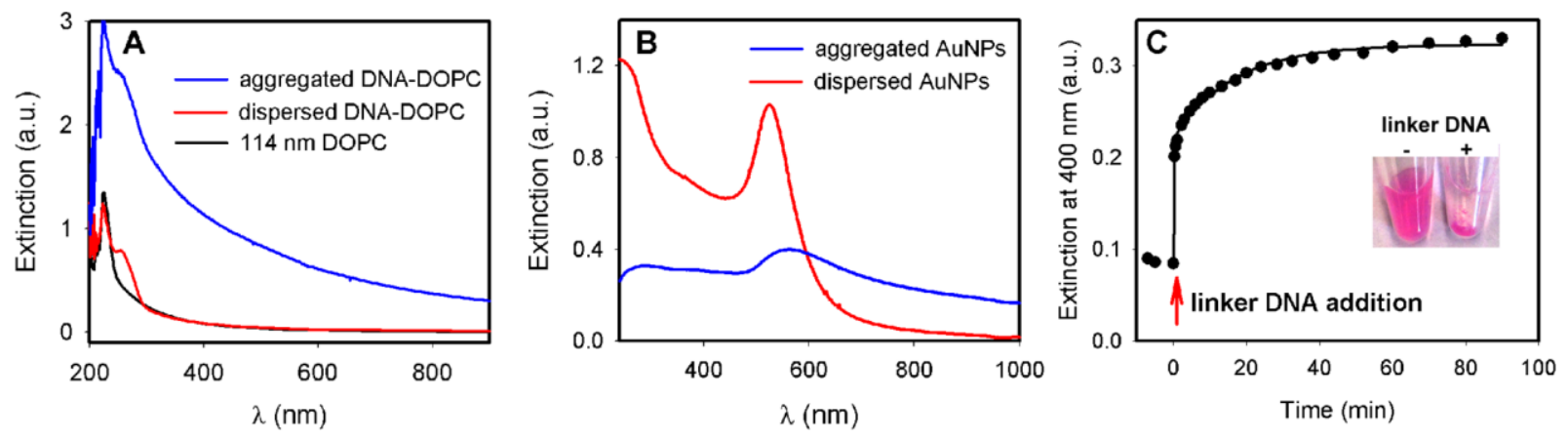

Figure 2. Extinction spectra of unmodified (black curve), DNA-modified dispersed (red curves) and assembled (blue curves) $114 \mathrm{~nm}$ DOPC liposomes (A) and $13 \mathrm{~nm}$ AuNPs (B). (C) Kinetics of DNAdirected assembly of liposomes. The assembly reaction was carried out in $300 \mathrm{mM} \mathrm{NaCl}, 20 \mathrm{mM}$ HEPES, pH 7.6 at $35{ }^{\circ} \mathrm{C}$ with $114 \mathrm{~nm}$ DOPC liposomes. Inset: a photograph of dispersed and assembled liposomes (with 1\% rhodamine-B label). Visible precipitates were formed upon DNAdirected assembly (the tube on the right), and its supernatant solution was clear, suggesting very few free liposomes were present. 
Assembly of DNA-Functionalized Liposomes. There are three methods to link DNA to a liposome. ${ }^{46}$ First, lipid-functionalized DNAs (e.g. with cholesterol) are incorporated during liposome preparation, resulting in DNA being present at both the inner and outer-leaflets of the bilayer membrane. This method requires a relatively large quantity of modified DNA and the stability of DNA insertion is low. ${ }^{47}$ In the second method, DNA-modified with certain lipids (e.g. cholesterol-TEG) can spontaneously and quantitatively insert themselves into pre-formed liposomes. ${ }^{48,49}$ One limitation is that only the $3^{\prime}$-end modification is commercially available for cholesterol-TEG. Many other reported lipid-DNA conjugates cannot be purchased from commercial sources and have to be synthesized in the researcher's own laboratory. ${ }^{27,29}$ We employed a third method where a small fraction (5\%) of lipid containing a reactive maleimide head group (MPB-PE) was first incorporated during liposome preparation. ${ }^{25}$ The maleimide group can react with thiol-modified DNA to produce a covalently linkage (Figure 1C). We achieved a coupling efficiency of $\sim 25 \%$, which was determined by the decrease in the DNA absorption peak at $260 \mathrm{~nm}$. Since both $3^{\prime}$ and 5'-thiol-modified DNAs and the reactive lipid are commercially available, this method can be readily used by most researchers.

A standard extrusion method was used to prepare liposomes of two sizes using polycarbonate membrane filters. For DOPC liposomes, dynamic light scattering showed that they had a hydrodynamic diameter of $114 \mathrm{~nm}$ and $251 \mathrm{~nm}$, respectively. The number of DNA molecules attached to each $114 \mathrm{~nm}$ liposome was determined to be 550 and to each $251 \mathrm{~nm}$ liposome to be 2100 (see Supporting Information). This density is slightly lower compared to that for DNA-functionalized AuNPs. For example, more than 8000 DNAs can be attached to each $250 \mathrm{~nm}$ AuNP. ${ }^{50}$

Unlike AuNPs, liposomes without a dye label do not possess an absorption feature in the visible region. Nevertheless, UV-vis spectroscopy can still be used to monitor the assembly process, since assembled liposomes reflect and scatter light more strongly in comparison to individually dispersed ones. A typical extinction spectrum of $114 \mathrm{~nm}$ DOPC liposome is shown in Figure 2A (black curve). 
After DNA attachment, a peak at $260 \mathrm{~nm}$ due to DNA absorption can be observed (red curve). Upon assembly via linker DNA, the extinction from 200 to $900 \mathrm{~nm}$ all increased (blue curve), with the extinction at shorter wavelengths being stronger. Therefore, any wavelength in this region can be used to monitor liposome aggregation. For most studies, we chose $260 \mathrm{~nm}$ to achieve a large signal change. It needs to be pointed out that the $260 \mathrm{~nm}$ extinction change is mostly due to the assembly of liposomes instead of the hypochromic effect of DNA hybridization, since the concentration of DNA is too low to contribute to such a large change. More importantly, DNA hybridization decreases the 260 extinction instead of increasing it. In the case of AuNP (Figure 2B), the extinction at $260 \mathrm{~nm}$ actually decreases upon aggregation (Figure 2B), which is related to the surface plasmon coupling of AuNPs. ${ }^{16}$

The kinetics of DNA-directed assembly of liposomes is presented in Figure 2C. After addition of $2 \mu \mathrm{M}$ linker DNA to the liposomes, the extinction at $400 \mathrm{~nm}$ started to increase immediately, indicating formation of aggregates. We chose to use $400 \mathrm{~nm}$ here to avoid artifacts associated with the absorption from the added linker DNA. A two-phase assembly process was observed. Initially the extinction increased rapidly, followed by a slow phase. By fitting the curve to a double exponential increase, we obtained rates of 7.1 and $0.061 \mathrm{~min}^{-1}$ for the two phases $\left(R^{2}=0.99\right)$. 
Melting Properties of DNA-Linked Liposomes. A key feature of DNA-linked AuNPs is their sharp melting transitions, ${ }^{16,17}$ which occur due to multivalent and cooperative DNA binding. To study DNAlinked liposomes, we first tested zwitterionic DOPC with a phase transition temperature $\left(\mathrm{T}_{\mathrm{c}}\right)$ of $-20{ }^{\circ} \mathrm{C}$. The assembled liposomes were dispersed in buffers with varying salt concentrations and the extinction at $260 \mathrm{~nm}$ was monitored as a function of temperature. Consistent with DNA-directed assembly, an increase in $T_{m}$ was found with increasing salt concentration (Figure 3A). Very sharp melting transitions were observed for all of the samples. The sharpness of the melting transition was determined by taking the full width at half-maximum (fwhm) of the first derivative of each melting curve, and the fwhm was found to be $1{ }^{\circ} \mathrm{C}$ or less. This sharpness compares favorably to that observed for AuNPs, ${ }^{17}$ indicating that the melting of liposomes shares the same cooperative mechanism.

One of the most unique properties of liposomes is their phase transition. Above $\mathrm{T}_{\mathrm{c}}$, the bilayer is fluid allowing fast lateral diffusion. Below this temperature, the bilayer is in a gel phase making diffusion more difficult. Since the DNAs were immobilized on the lipid head group, the membrane fluidity may affect the local DNA density, packing, and dynamics, which may in turn affect the number of DNA linkages between liposomes and the $\mathrm{T}_{\mathrm{m}}$ of DNA in the liposome aggregates. All the DNA melting transitions occurred above the $\mathrm{T}_{\mathrm{c}}$ of $\mathrm{DOPC}\left(-20^{\circ} \mathrm{C}\right)$ in the previous experiment. To test the effect of lipid fluidity, DPPC liposomes with a $\mathrm{T}_{\mathrm{c}}=41^{\circ} \mathrm{C}$ were also studied (Figure 3B). DPPC has a higher $\mathrm{T}_{\mathrm{c}}$ due to a better packing of the hydrocarbon chains (i.e. the double bonds in DOPC result in kink formation). Interestingly, the overall salt-dependent melting trend and $\mathrm{T}_{\mathrm{m}}$ values were very close to those observed for DOPC. At low salt concentrations (e.g. $6 \mathrm{mM})$, DNA melted prior to DPPC phase transition. At high salt concentrations (e.g. $52 \mathrm{mM}$ ), DNA melted after the lipid phase transition. Under our experimental conditions, the similarity in $\mathrm{T}_{\mathrm{m}}$ between DPPC and DOPC suggests that lipid fluidity has little effects on the melting of the liposome aggregates. For all of the DPPC melting curves, we observed a second transition at $\sim 41{ }^{\circ} \mathrm{C}$ (a small drop in the extinction), which coincides with the $\mathrm{T}_{\mathrm{c}}$ of 
this lipid. To confirm the origin of this second transition, we monitored the extinction of nonfunctionalized DPPC liposomes (no DNA), and a drop in extinction at this temperature was also observed (see Supporting Information). However, non-functionalized DOPC did not show an obvious temperature-dependent extinction change. Therefore, this second transition is attributed to the phase transition of DPPC. For comparison purposes, we also conducted melting studies of $13 \mathrm{~nm}$ AuNPs assembled by the same linker DNA. As shown in Figure 3C, the resulting $\mathrm{T}_{\mathrm{m}}$ 's are very similar to those obtained for the liposome aggregates. Because the AuNPs and liposomes were quite different in size and as will be discussed later, nanoparticle size plays a crucial role in determining the $\mathrm{T}_{\mathrm{m}}$ in AuNPs, this similarity $\mathrm{T}_{\mathrm{m}}$ is more of a coincidence rather than a general observation.
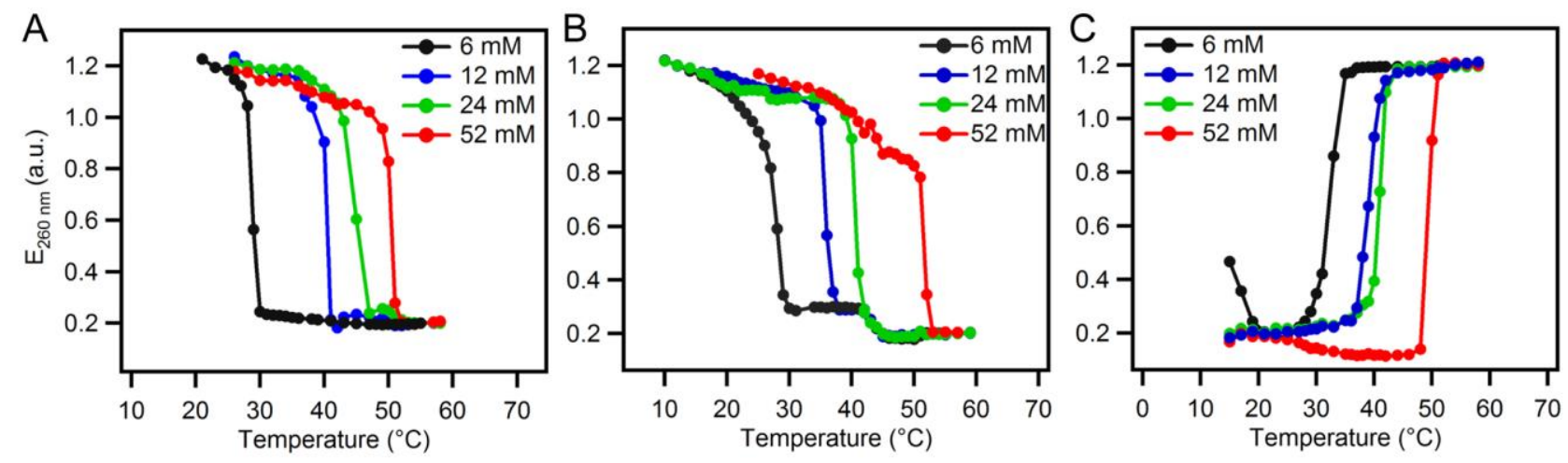

Figure 3. Salt-dependent melting curves of DNA-linked DOPC (A), DPPC (B) and AuNPs (C). All these nanomaterials were assembled using the same linker DNA. The melting curves are normalized for comparison of the melting transitions. 
Effect of Liposome Charge and Cholesterol. The surface property of liposomes can be controlled by mixing different lipids during liposome preparation. Taking advantage of this property, we next studied the effect of surface charge by using negatively charged DOPG. As shown in Figure 4A, there was no difference in the $T_{m}$ value or the melting transition sharpness when anionic DOPG was used, or zwitterionic DOPC or their 1:1 mixture. At $52 \mathrm{mM} \mathrm{Na}^{+}$, all the three liposome aggregates showed a sharp melting transition with $\mathrm{T}_{\mathrm{m}}=\sim 50^{\circ} \mathrm{C}$. Therefore, surface charge appeared to have little influence on the melting behavior of DNA-linked liposomes.

The interaction between charged liposomes in an electrolyte solution can be described using the DLVO theory. In the absence of DNA, long-range van der Waals attractive forces and long-rang electrostatic repulsive forces govern liposome interactions. In the presence of a rigid B-form 24-mer double-stranded DNA linker, the liposomes are separated by $\sim 8 \mathrm{~nm}$. There was also a 9-adenine spacer on each end (see Figure 5A). Therefore the liposomes are separated by $\sim 10 \mathrm{~nm}$ in the assembled state. Based on the literature reported calculations for charged liposomes separated by $10 \mathrm{~nm}$, the interaction energy was only $\sim 1 k_{B} T$, the thermal energy. ${ }^{51}$ At $298 \mathrm{~K}$, this energy is $\sim 0.6 \mathrm{kcal} / \mathrm{mol}$. The 12 -mer DNA base pairing free energy in our system should be greater than $6 \mathrm{kcal} / \mathrm{mol} .{ }^{52,53}$ Considering that liposomes are linked by multiple DNAs, the energy from DNA binding is even greater. Therefore, other inter-liposome forces are much smaller in comparison to the DNA hybridization energy, which may explain why liposome charge has little effect on the $\mathrm{T}_{\mathrm{m}}$.

To further understand the effect of surface charge, the $\xi$-potential of the liposomes were measured. At pH 7.6 with $52 \mathrm{mM} \mathrm{Na}{ }^{+}$, DOPC showed a $\xi$-potential of $-7.0 \mathrm{mV}$, which was consistent with literature reports that the PC head group carries a slight negative charge at neutral $\mathrm{pH} .{ }^{54}$ After attaching DNA, its $\xi$-potential changed to $-19.7 \mathrm{mV}$ because DNA is a polyanion and can increase surface negative charge. On the other hand, DOPG showed a potential of $-51.8 \mathrm{mV}$ and $-39.4 \mathrm{mV}$, respectively, before and after attaching DNA. This suggests that the charge density at the plane of shear 
actually decreased for DOPG after DNA attachment. Therefore, DNA had an averaging effect on the surface charge: the $\xi$-potential difference between DOPG and DOPC decreased from $45 \mathrm{mV}$ to $20 \mathrm{mV}$ after DNA attachment, which may also contribute to the observed charge-independence on the melting transitions.

While the melting of DOPC and DPPC was compared in Figure 3, we further studied the effect of adding cholesterol, which is an important component in the cell membrane and is known to have an averaging effect on the lipid phase transition. Cholesterol can fluidize the gel phase lipids while making lipids like DOPC less fluid. ${ }^{55}$ With $30 \%$ (w/w) cholesterol in DOPC, the melting curve still overlaps with those pure PC liposomes in the transition region (Figure 4B). Therefore, it appears that neither charge nor lipid fluidity has much effect on the melting behavior of the assembled structures; DNA hybridization alone governs the melting property.
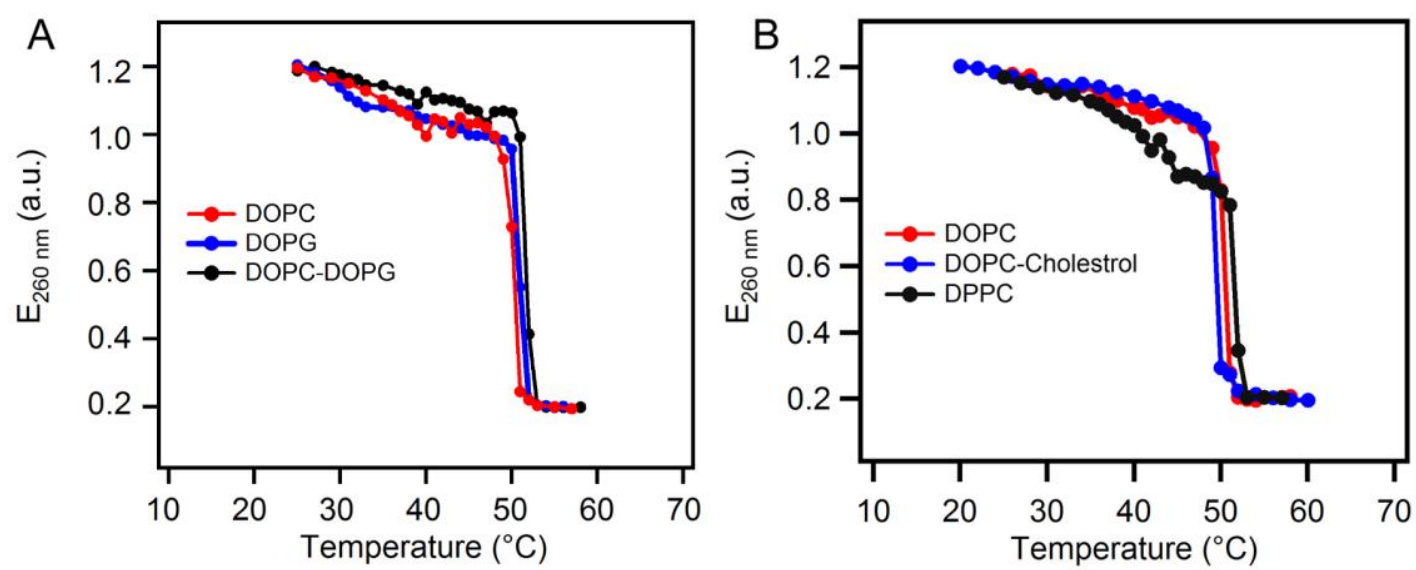

Figure 4. Melting curves of DNA-linked liposomes as a function of liposome charge (A) and composition (B). All of the liposomes were assembled using the same linker DNA sequence. 
Effect of a DNA Spacer. It has been shown that the melting of DNA-linked AuNPs is strongly affected by the presence of a polynucleotide spacer introduced between the hybridization sequence and thiol group. ${ }^{17}$ The inter-particle distance was increased by the spacer, resulting in a higher $\mathrm{T}_{\mathrm{m}}$. In all of the experiments conducted so far, a 9-adenine ( $\left.\mathrm{A}_{9}\right)$ spacer was used as illustrated in Figure 5A. To test its effect in the liposome system, thiol-modified DNAs without the A9 spacer were also used for liposome functionalization. Interestingly little difference was observed in the $\mathrm{T}_{\mathrm{m}}$ for liposome aggregates prepared with and without the A9 spacer (Figure 5B); while AuNPs clearly show a much higher $\mathrm{T}_{\mathrm{m}}$ when the $\mathrm{A}_{9}$ spacer was used (Figure 5C). This experiment illustrates an interesting difference between hard and soft nanoparticles. Soft materials such as liposomes may be better at adjusting themselves (e.g. through liposome deformation and DNA diffusion within the bilayer) in response to the pressure and crowdedness caused by the assembly process.
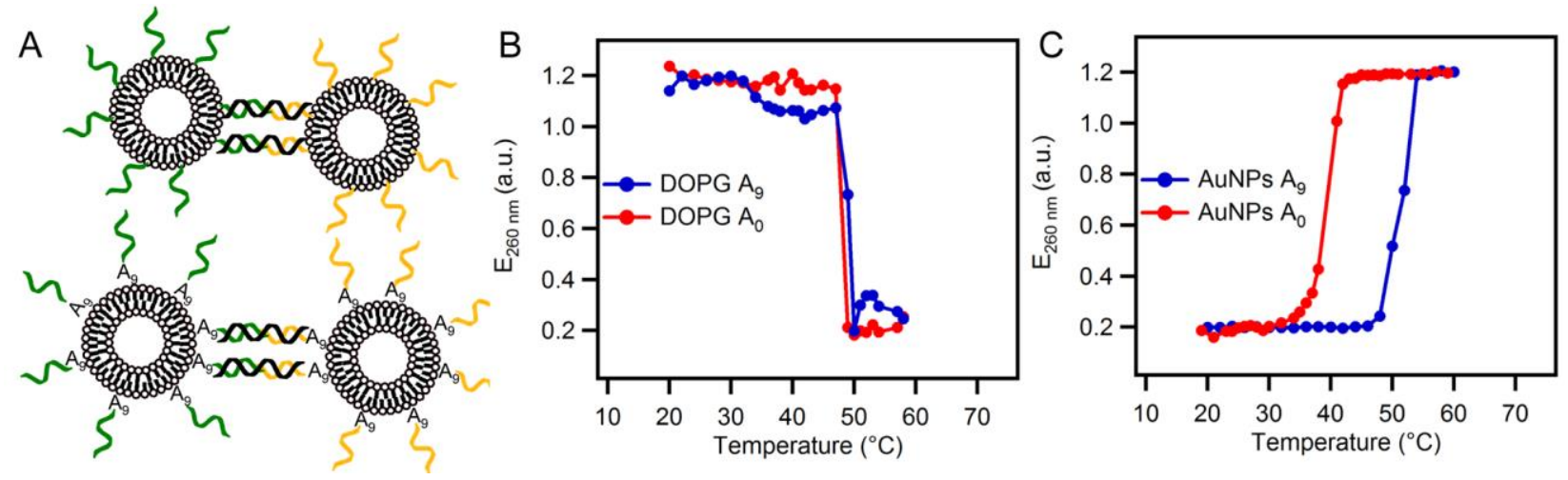

Figure 5. (A) Schematic presentation of liposome aggregates containing either no spacer (the upper panel) or a 9-adenine (A9) spacer (the lower panel). Melting curves of DOPG liposomes (B) and AuNPs (C) in the presence and absence of the A9 spacer. 
Effect of Liposome Size. One important aspect of nanoscience is to study size-dependent properties of nanomaterials. It has been recently demonstrated that AuNPs with a diameter up to $250 \mathrm{~nm}$ can be functionalized with DNA. ${ }^{50}$ In the case of liposomes, it is also possible to prepare a wide range of sizes with good colloidal stability. We have made DOPC liposomes with average sizes of 114 and $251 \mathrm{~nm}$. All previous melting data were collected with the $114 \mathrm{~nm}$ liposomes. To test the effect of liposome size, both liposomes were assembled using the same linker DNA and we did not observe a significant difference in the $T_{m}$ or the sharpness of the melting transition (with $52 \mathrm{mM} \mathrm{Na}^{+}$, Figure $6 \mathrm{~A}$ ). On the other hand, $50 \mathrm{~nm}$ AuNPs melted at a temperature of $12{ }^{\circ} \mathrm{C}$ higher than $13 \mathrm{~nm}$ ones (Figure 6B). This result is consistent with reports from other research groups that larger AuNPs show a higher $T_{m}$ in DNA-linked nanostructures. ${ }^{56-59}$ For example, Mirkin and coworkers reported a $7{ }^{\circ} \mathrm{C}$ increase in $\mathrm{T}_{\mathrm{m}}$ by increasing the AuNP size from 80 to $150 \mathrm{~nm} .{ }^{56,57}$ There are a number of factors that can affect the $\mathrm{T}_{\mathrm{m}}$ of DNA-linked nanoparticles, including DNA sequence, length, DNA density on the particles, solution ionic strength, $\mathrm{pH}$, and particle size. If all of the other parameters are fixed and only the particle size is increased, an increased $\mathrm{T}_{\mathrm{m}}$ should be observed due to an increase in the contact area resulting in more DNA linkages, which has been used to explain the size-dependent $\mathrm{T}_{\mathrm{m}}$ of AuNPs. ${ }^{56}$

The DNA density on our liposomes was about one quarter of that on AuNPs, and this may explain why our $114 \mathrm{~nm}$ liposomes showed a similar $T_{m}$ as $13 \mathrm{~nm}$ AuNPs. Our 114 and $251 \mathrm{~nm}$ liposomes had on average 550 and 2100 thiol-modified DNA attached, respectively. Therefore, the DNA densities for both liposomes were similar, and we cannot use this to explain the size-independent melting. Since the DNA molecules are linked to the MPB-modified PE lipid, which has a saturated lipid tail (Figure 1C), these lipid molecules may form microdomains in the DOPC liposomes whose $\mathrm{T}_{\mathrm{c}}$ is $-20{ }^{\circ} \mathrm{C}$. The labeled DNA might then be concentrated within these domains. If the size of the microdomains is independent of the liposome diameter then we can explain the melting observation. In order to test this, another MPB-labeled PE lipid with an unsaturated tail was also used to conjugate 
DNA. This new PE lipid should have a $\mathrm{T}_{\mathrm{c}}$ closer to that of DOPC. Therefore, the possibility of microdomain formation should be much lower (given that the negatively charged DNA should be repulsive to each other). However, the same size-independency was also obtained in this studying (see Supporting Information, Figure S3).

We attribute this size-independent melting behavior to the fluidity of the bilayer membrane. Unlike in the case of AuNPs, where each thiol-modified DNA is fixed in place, the DNA attached to the liposomes can diffuse laterally. Once a DNA linkage is melted, the involved DNA can diffuse away and the chance for it to re-hybridize at a temperature close to $T_{m}$ is low. This may effectively decrease the number of linkages prior to the melting transition and explain why increasing the liposome size did not increase $T_{m}$. The fact that the melting transitions remained quite sharp for liposomes suggests that a sufficient number of DNA linkages were still present prior to the transition to allow cooperative melting.
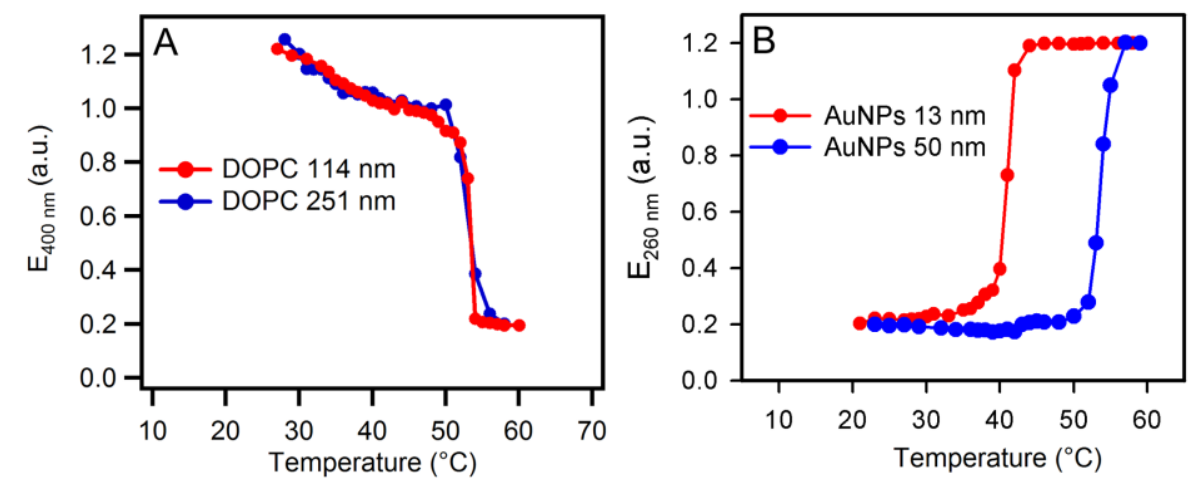

Figure 6. (A) Melting curves of DNA-linked 114 and $251 \mathrm{~nm}$ DOPC liposomes in $52 \mathrm{mM} \mathrm{Na}^{+}$. (B) Melting curves of DNA-linked 13 and $50 \mathrm{~nm}$ AuNPs in $24 \mathrm{mM} \mathrm{Na}^{+}$. 
Cryo-TEM Studies. To study the structure and morphology of DNA-linked liposomes, cryo-TEM experiments were performed. Both $103 \mathrm{~nm}$ and a mixture of 103 and $258 \mathrm{~nm}$ liposomes were assembled by linker DNA. Since the aggregates were very large, only the edges were imaged so that the electrons could penetrate through. The $103 \mathrm{~nm}$ liposomes were spherical with a membrane thickness of $\sim 5 \mathrm{~nm}$, suggestive of a unilamellar membrane (Figure 7A). The average size agrees with the dynamic light scattering results. Some deformation from the spherical shape can be observed, which may be caused by the pressure from nearby liposomes during aggregation. In the aggregates containing both 103 and $258 \mathrm{~nm}$ liposomes, both sized populations can be observed and the smaller ones arranged around and bridged with the large ones. Some of the larger liposomes appeared to be multi-lamellar or encapsulating smaller ones (Figure 7B). More cryo-TEM images showing a larger area are presented in the Supporting Information. This experiment further supports that DNA-linked liposomes have been prepared and good programmability can be achieved.

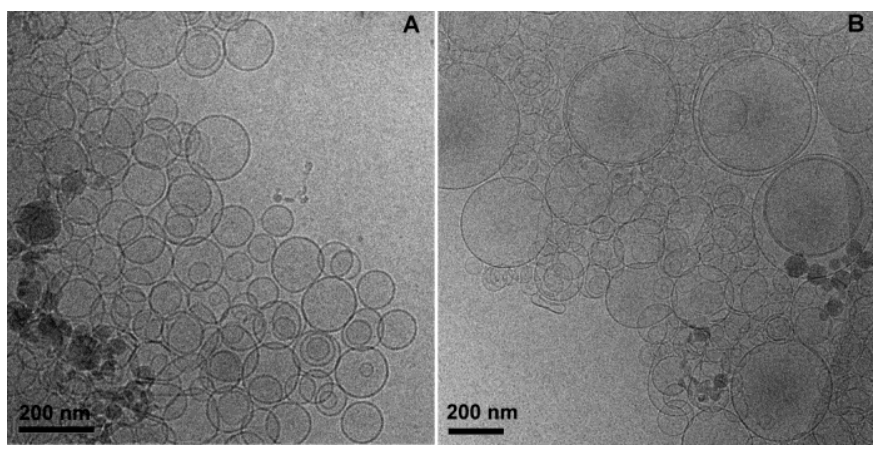

Figure 7. Cryo-TEM micrographs of DNA linked $103 \mathrm{~nm}(\mathrm{~A})$ and 103/258 nm (B) liposomes. 
The Effect of Mismatches in the Linker DNA. One important analytical application of DNA-directed assembly is to detect the linker DNA sequence. ${ }^{19,27}$ Because of the sharp melting transitions, even single base mismatches can be detected with high selectivity. We further studied whether our liposome aggregates can differentiate such mismatches (Figure 8A). A perfectly complementary linker gives a $\mathrm{T}_{\mathrm{m}}$ of $51{ }^{\circ} \mathrm{C}$ (Figure $8 \mathrm{~B}$ ). However when there was a single base deletion or insertion, the $\mathrm{T}_{\mathrm{m}}$ dropped to $48{ }^{\circ} \mathrm{C}$ and $49{ }^{\circ} \mathrm{C}$, respectively. This was similar to what was reported for AuNP probes. ${ }^{18}$ On the other hand, single nucleotide mismatches led to $\mathrm{T}_{\mathrm{m}}$ 's in the range of $38-41{ }^{\circ} \mathrm{C}$. This was because the mismatches were positioned in the middle of the hybridization sequence instead of the end, leading to a larger destabilization effect. Again, all of the samples showed very sharp melting transitions. Therefore, DNA-directed assembly of liposomes could also be used for highly selective DNA detection.
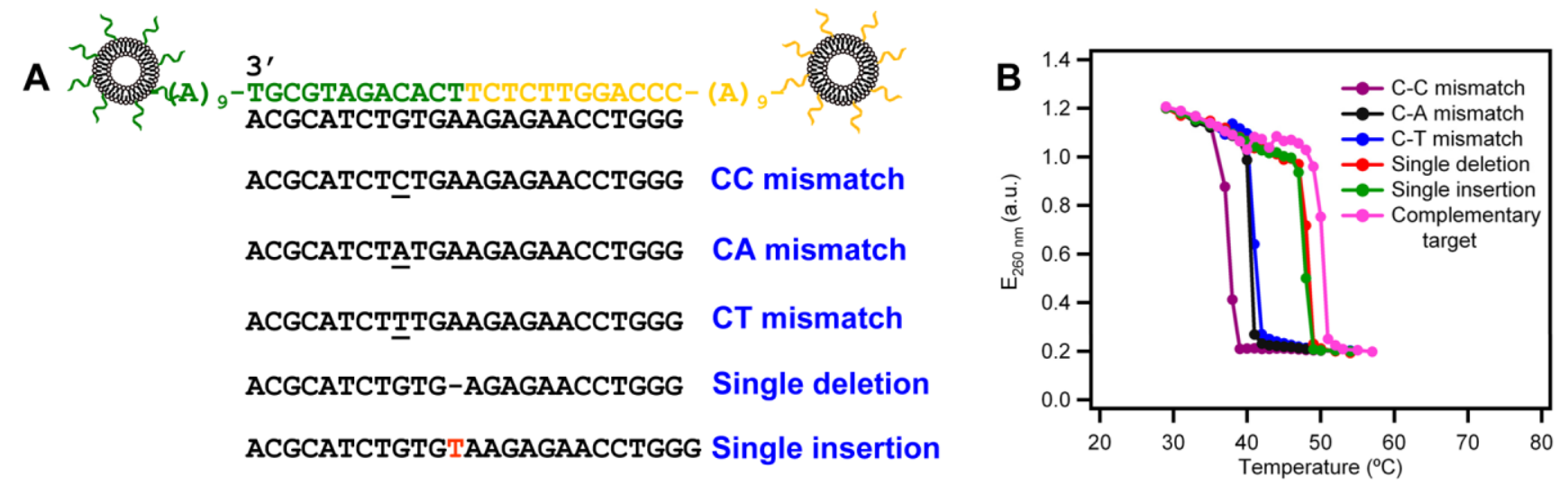

Figure 8. (A) The different linker DNA sequences used for studying the effect of mismatches. (B) Melting curves of DOPC liposome aggregates prepared with mismatch linker DNAs. 
In summary, we have demonstrated DNA-directed assembly of DNA-functionalized liposomes in a three-component system. This is the first systematic study on the physical properties of DNAlinked liposomes where various liposome formulations and DNA sequences have been tested; all were based on the same conjugation chemistry, suggesting good generality and programmability of our method. The melting transitions of these liposome assemblies as a function of lipid charge, size, fluidity, and attached DNA have been systematically studied and compared with those properties of AuNPs. While there are many similarities, important differences exist. For example, the $\mathrm{T}_{\mathrm{m}}$ of liposome assemblies is less affected by the inter-particle separation or liposome size. These differences may be explained by the soft nature of liposomes compared to AuNPs. Such fundamental understandings may improve our design of new liposome-based materials for both analytical and biomedical applications.

\section{Materials and Methods}

Chemicals. The DNA samples were purchased from Integrated DNA Technologies (Coralville, IA). The phospholipids were purchased from Avanti Polar Lipids (Alabaster, AL). Cholesterol and chloroform were purchased from VWR. Tris(2-carboxyethyl)phosphine (TCEP) was purchased from Sigma. Citrate reduced AuNPs (13 nm diameter) were prepared according to a previously published method. ${ }^{18}$ AuNPs $(50 \mathrm{~nm})$ were purchased from Ted Pella Inc (Redding, CA). The phospholipids used in this study are listed below: 1,2-dioleoyl-sn-glycero-3-phosphocholine (DOPC); 1,2-dioleoyl-snglycero-3-phospho-(1'-rac-glycerol) (sodium salt) (DOPG); 1,2-dihexadecanoyl-sn-glycero-3phosphocholine (DPPC); 1,2-dioleoyl-sn-glycero-3-phosphoethanolamine-N-(lissamine rhodamine B sulfonyl) (ammonium salt) (Rh-PE), 1,2-dipalmitoyl-sn-glycero-3-phosphoethanolamine-N-[4-(pmaleimidophenyl)butyramide] (MPB-PE), and 1,2-dioleoyl-sn-glycero-3-phosphoethanolamine-N-[4(p-maleimidophenyl)butyramide] (18:1 MPB-PE). 
Preparation of Liposomes. Liposomes were prepared using the standard extrusion method. Lipids were mixed at designated ratios with a total mass of $2.5 \mathrm{mg}$ in chloroform, and all of the samples contained 5\% MPB-PE. Chloroform was removed under a gentle $\mathrm{N}_{2}$ flow in the fume hood and trace amounts of residual chloroform was removed by storing the samples under vacuum overnight at room temperature. The dried lipids were kept under a $\mathrm{N}_{2}$ environment and then stored at $-20{ }^{\circ} \mathrm{C}$ prior to use. To prepare liposomes, the lipids were rehydrated with $0.5 \mathrm{~mL}$ buffer A $(150 \mathrm{mM} \mathrm{NaCl}, 25 \mathrm{mM}$ HEPES, $\mathrm{pH}$ 7.6) at room temperature with occasional sonication. Therefore, the lipid concentration was $5 \mathrm{mg} / \mathrm{mL}$. After the lipids were fully hydrated for $\sim 1 \mathrm{hr}$, a cloudy suspension was obtained. This lipid was extruded through a polycarbonate membrane (pore size $=50$ or $400 \mathrm{~nm}$ ) 21 times. After extrusion, the lipid solution appeared to be transparent, indicating the formation of liposomes. The prepared liposomes were immediately used for DNA conjugation. Since DPPC has a $\mathrm{T}_{\mathrm{c}}=41{ }^{\circ} \mathrm{C}$, a water bath was heated to $\sim 60{ }^{\circ} \mathrm{C}$ to rehydrate DPPC and extrusion was also performed at this temperature.

DNA Conjugation to Liposomes and AuNPs. Thiol-modified DNAs were activated with TCEP (TCEP:DNA = 2:1 molar ratio) in $40 \mathrm{mM}$ acetate buffer $\mathrm{pH} 5.0$ for at least $1 \mathrm{hr}$ at room temperature. $50 \mu \mathrm{L}$ of $5 \mathrm{mg} / \mathrm{mL}$ liposomes were reacted with $60 \mu \mathrm{M}$ activated DNA at room temperature overnight in buffer A. After incubation, the salt was adjusted to $500 \mathrm{mM} \mathrm{NaCl}$ and the sample was stored at $4{ }^{\circ} \mathrm{C}$ for $12 \mathrm{hrs}$. We found that the liposomes precipitated out of solution, which was attributed to the selfaggregation of the DNA-functionalized liposomes. ${ }^{56}$ These liposomes were harvested after centrifugation $(13000 \mathrm{rpm})$ at $4{ }^{\circ} \mathrm{C}$ and unreacted DNA in the supernatant was removed. Using the rhodamine-B-labeled liposome, we found that $>95 \%$ of liposomes were recovered by this centrifugation step. The liposomes were then dispersed at a concentration of $2.5 \mathrm{mg} / \mathrm{mL}$ in buffer A. Thiol-modified DNAs were attached to 13 and $50 \mathrm{~nm}$ AuNPs according to published protocols. ${ }^{50,60}$ 
Preparation of DNA-Linked Aggregates. In a typical reaction, $0.25 \mathrm{mg} / \mathrm{mL}$ of each liposomes (functionalized respectively with $3^{\prime}$ and 5'-end thiol-modified DNA) and $2.5 \mu \mathrm{M}$ linker DNA were mixed in buffer $\mathrm{B}\left(300 \mathrm{mM} \mathrm{NaCl}\right.$ with $25 \mathrm{mM}$ HEPES, pH 7.6). The mixture was incubated at $50{ }^{\circ} \mathrm{C}$ for $5 \mathrm{~min}$ and then allowed to cool slowly to $35^{\circ} \mathrm{C}$. To prepare AuNP aggregates, $4.5 \mathrm{nM}$ of each functionalized AuNPs were mixed with $0.2 \mu \mathrm{M}$ linker DNA in buffer B.

Melting Curves and Kinetics. For melting temperature measurement, DNA-linked aggregates were dispersed in a final volume of $200 \mu \mathrm{L}$ of a buffer of choice containing varying concentrations of $\mathrm{NaCl}$ and HEPES at $\mathrm{pH}$ 7.6. The aggregates were repeatedly dispersed in $200 \mu \mathrm{L}$ of the cold buffer, centrifuged to remove the supernatant and re-dispersed in the same buffer at $4{ }^{\circ} \mathrm{C}$ four times prior to the melting experiment. The measurements were performed with an Agilent 8453 spectrophotometer. The temperature was controlled by a circulating water bath. The initial temperature increment was every $2{ }^{\circ} \mathrm{C}$ and then every $1{ }^{\circ} \mathrm{C}$ close to $\mathrm{T}_{\mathrm{m}}$. The samples were allowed to equilibrate at each designated temperature for $2 \mathrm{~min}$ before measurement. The melting curves were obtained by plotting the extinction at $260 \mathrm{~nm}$ as a function of temperature. To compare different samples, the melting curves were normalized linearly to have the lowest extinction at 0.2 and highest extinction at 1.2 . The first derivative of a melting curve was used to determine the $\mathrm{T}_{\mathrm{m}}$. To measure the kinetics of liposome aggregation, an equal concentration of $3^{\prime}-$ and 5' thiol-DNA functionalized DOPC liposomes $(0.2$ $\mathrm{mg} / \mathrm{mL})$ were mixed in buffer $\mathrm{B}$ at $35^{\circ} \mathrm{C}$. Linker DNA $(2 \mu \mathrm{M})$ was added and the extinction spectra were collected up to $90 \mathrm{~min}$.

Dynamic Light Scattering and $\xi$-Potential Measurements. To estimate the size and charge of the liposomes, dynamic light scattering and $\xi$-potential experiments were performed using a Malvern Zetasizer Nano instrument. The freshly prepared liposomes and DNA conjugated liposomes were dispersed in a buffer containing $100 \mathrm{mM} \mathrm{NaCl}, 25 \mathrm{mM}$ HEPES at $\mathrm{pH} 7.6$ at a lipid concentration of 
$0.25 \mathrm{mg} / \mathrm{mL}$ for size measurement. To measure the $\xi$-potential, a buffer containing $52 \mathrm{mM} \mathrm{NaCl}$ was used.

Cryo-TEM. The DNA-linked liposomes (DOPC containing 30\% cholesterol with 5\% DOPG and 5\% MPB-PE) were dispersed in a buffer containing $40 \mathrm{mM} \mathrm{NaCl}$ and $10 \mathrm{mM}$ HEPES pH 7.6. TEM samples were prepared by spotting $5 \mu \mathrm{L}$ of the liposome suspension on a carbon coated copper TEM grid (treated with plasma to ensure surface was hydrophilic) in a humidity controlled chamber (FEI Vitrobot). The humidity was set to be 95 to $100 \%$ during this operation. The grid was blotted with two filter papers for $1.5 \mathrm{sec}$ and quickly plunged into liquid ethane. The sample was then loaded to a liquid $\mathrm{N}_{2}$ cooled cold stage and loaded into a $200 \mathrm{kV}$ field emission TEM (FEI Tecnai G2 F20). The samples were imaged when the temperature was stabilized at $-175^{\circ} \mathrm{C}$.

ACKNOWLEDGMENT. We thank Mr. Robert Harris at the University of Guelph for assistance with the cryo-TEM experiment. Funding for this work is from the University of Waterloo and the Discovery Grant of the Natural Sciences and Engineering Research Council (NSERC) of Canada.

Supporting Information Available. DNA quantification, additional melting curves and cryo-TEM micrographs. This material is available free of charge via the Internet at http://www.acs.org.

\section{Reference:}

1. Mirkin, C. A., Letsinger, R. L., Mucic, R. C., and Storhoff, J. J. A DNA-Based Method for Rationally Assembling Nanoparticles into Macroscopic Materials. Nature 1996, 382, 607-609.

2. Alivisatos, A. P., Johnsson, K. P., Peng, X., Wilson, T. E., Loweth, C. J., Bruchez, M. P., Jr, and Schultz, P. G. Organization of 'Nanocrystal Molecules' Using DNA. Nature 1996, 382, 609611. 
3. Storhoff, J. J., and Mirkin, C. A. Programmed Materials Synthesis with DNA. Chem. Rev. 1999, 99, 1849-1862.

4. Seeman, N. C. DNA in a Material World. Nature 2003, 421, 427-431.

5. Katz, E., and Willner, I. Nanobiotechnology: Integrated Nanoparticle-Biomolecule Hybrid Systems: Synthesis, Properties, and Applications. Angew. Chem., Int. Ed. 2004, 43, 6042-6108.

6. Feldkamp, U., and Niemeyer, C. M. Rational Design of DNA Nanoarchitectures. Angew. Chem., Int. Ed. 2006, 45, 1856-1876.

7. Lu, Y., and Liu, J. Smart Nanomaterials Inspired by Biology: Dynamic Assembly of Error-Free Nanomaterials in Response to Multiple Chemical and Biological Stimuli. Acc. Chem. Res. 2007, 40, 315-323.

8. Aldaye, F. A., Palmer, A. L., and Sleiman, H. F. Assembling Materials with DNA as the Guide. Science 2008, 321, 1795-1799.

9. Rosi, N. L., and Mirkin, C. A. Nanostructures in Biodiagnostics. Chem. Rev. 2005, 105, 15471562.

10. Cheng, W. L., Campolongo, M. J., Cha, J. J., Tan, S. J., Umbach, C. C., Muller, D. A., and Luo, D. Free-Standing Nanoparticle Superlattice Sheets Controlled by DNA. Nat. Mater. 2009, 8, 519-525.

11. Lin, C., Liu, Y., and Yan, H. Designer DNA Nanoarchitectures. Biochemistry 2009, 48, 16631674.

12. Ding, B. Q., Deng, Z. T., Yan, H., Cabrini, S., Zuckermann, R. N., and Bokor, J. Gold Nanoparticle Self-Similar Chain Structure Organized by DNA Origami. J. Am. Chem. Soc. 2010, 132, 3248-3249.

13. Stearns, L. A., Chhabra, R., Sharma, J., Liu, Y., Petuskey, W. T., Yan, H., and Chaput, J. C. Template-Directed Nucleation and Growth of Inorganic Nanoparticles on DNA Scaffolds. Angew. Chem. Int. Ed. 2009, 48, 8494-8496. 
14. Liu, J., Cao, Z., and Lu, Y. Functional Nucleic Acid Sensors. Chem. Rev. 2009, 109, 19481998.

15. Zhao, W., Brook, M. A., and Li, Y. Design of Gold Nanoparticle-Based Colorimetric Biosensing Assays. Chembiochem 2008, 9, 2363-2371.

16. Storhoff, J. J., Lazarides, A. A., Mucic, R. C., Mirkin, C. A., Letsinger, R. L., and Schatz, G. C. What Controls the Optical Properties of DNA-Linked Gold Nanoparticle Assemblies? J. Am. Chem. Soc. 2000, 122, 4640-4650.

17. Jin, R., Wu, G., Li, Z., Mirkin, C. A., and Schatz, G. C. What Controls the Melting Properties of DNA-Linked Gold Nanoparticle Assemblies? J. Am. Chem. Soc. 2003, 125, 1643-1654.

18. Storhoff, J. J., Elghanian, R., Mucic, R. C., Mirkin, C. A., and Letsinger, R. L. One-Pot Colorimetric Differentiation of Polynucleotides with Single Base Imperfections Using Gold Nanoparticle Probes. J. Am. Chem. Soc. 1998, 120, 1959-1964.

19. Elghanian, R., Storhoff, J. J., Mucic, R. C., Letsinger, R. L., and Mirkin, C. A. Selective Colorimetric Detection of Polynucleotides Based on the Distance-Dependent Optical Properties of Gold Nanoparticles. Science 1997, 277, 1078-1080.

20. LaVan, D. A., McGuire, T., and Langer, R. Small-Scale Systems for in Vivo Drug Delivery. Nat. Biotechnol. 2003, 21, 1184-1191.

21. Collier, J. H., and Messersmith, P. B. Phospholipid Strategies in Biomineralization and Biomaterials Research. Annu. Rev. Mater. Res. 2001, 31, 237-263.

22. Liang, H. J., Angelini, T. E., Ho, J., Braun, P. V., and Wong, G. C. L. Molecular Imprinting of Biomineralized Cds Nanostructures: Crystallographic Control Using Self-Assembled DNAMembrane Templates. J. Am. Chem. Soc. 2003, 125, 11786-11787.

23. Zhang, L. F., Hong, L., Yu, Y., Bae, S. C., and Granick, S. Nanoparticle-Assisted Surface Immobilization of Phospholipid Liposomes. J. Am. Chem. Soc. 2006, 128, 9026-9027. 
24. Jesorka, A., and Orwar, O. Liposomes: Technologies and Analytical Applications. Annu. Rev. Anal. Chem. 2008, 1, 801-832.

25. Yoshina-Ishii, C., and Boxer, S. G. Arrays of Mobile Tethered Vesicles on Supported Lipid Bilayers. J. Am. Chem. Soc. 2003, 125, 3696-3697.

26. Cao, Z. H., Tong, R., Mishra, A., Xu, W. C., Wong, G. C. L., Cheng, J. J., and Lu, Y. Reversible Cell-Specific Drug Delivery with Aptamer-Functionalized Liposomes. Angew. Chem. Int. Ed. 2009, 48, 6494-6498.

27. Jakobsen, U., Simonsen, A. C., and Vogel, S. DNA-Controlled Assembly of Soft Nanoparticles. J. Am. Chem. Soc. 2008, 130, 10462-10463.

28. Zhang, G. R., Farooqui, F., Kinstler, O., and Letsinger, R. L. Informational Liposomes: Complexes Derived from Cholesteryl-Conjugated Oligonucleotides and Liposomes. Tetrahedron Lett. 1996, 37, 6243-6246.

29. Chan, Y. H. M., van Lengerich, B., and Boxer, S. G. Effects of Linker Sequences on Vesicle Fusion Mediated by Lipid-Anchored DNA Oligonucleotides. Proc. Natl. Acad. Sci. U.S.A. 2009, 106, 979-984.

30. Chan, Y. H. M., Lenz, P., and Boxer, S. G. Kinetics of DNA-Mediated Docking Reactions between Vesicles Tethered to Supported Lipid Bilayers. Proc. Natl. Acad. Sci. U.S.A. 2007, $104,18913-18918$.

31. Yoshina-Ishii, C., Miller, G. P., Kraft, M. L., Kool, E. T., and Boxer, S. G. General Method for Modification of Liposomes for Encoded Assembly on Supported Bilayers. J. Am. Chem. Soc. $\mathbf{2 0 0 5}, 127,1356-1357$.

32. Stengel, G., Simonsson, L., Campbell, R. A., and Hook, F. Determinants for Membrane Fusion Induced by Cholesterol-Modified DNA Zippers. J. Phys. Chem. B 2008, 112, 8264-8274.

33. Stengel, G., Zahn, R., and Hook, F. DNA-Induced Programmable Fusion of Phospholipid Vesicles. J. Am. Chem. Soc. 2007, 129, 9584-9585. 
34. Jakobsen, U., and Vogel, S. DNA-Controlled Assembly of Liposomes in Diagnostics. Meth. Enzymol. 2009, 464, 233-248.

35. Wang, C. G., and Ma, Z. F. Colorimetric Detection of Oligonucleotides Using a Polydiacetylene Vesicle Sensor. Anal. Bioanal. Chem. 2005, 382, 1708-1710.

36. Lozano, M. M., Starkel, C. D., and Longo, M. L. Vesicles Tethered to Microbubbles by Hybridized DNA Oligonucleotides: Flow Cytometry Analysis of This New Drug Delivery Vehicle Design. Langmuir 2010.

37. Chandra, R. A., Douglas, E. S., Mathies, R. A., Bertozzi, C. R., and Francis, M. B. Programmable Cell Adhesion Encoded by DNA Hybridization. Angew. Chem. Int. Ed. 2006, 45, 896-901.

38. Gartner, Z. J., and Bertozzi, C. R. Programmed Assembly of 3-Dimensional Microtissues with Defined Cellular Connectivity. Proc. Natl. Acad. Sci. U.S.A. 2009, 106, 4606-4610.

39. Loew, M., Kang, L., Dahne, L., Hendus-Altenburger, R., Kaczmarek, O., Liebscher, J., Huster, D., Ludwig, K., Bottcher, C., Herrmann, A., et al. Controlled Assembly of Vesicle-Based Nanocontainers on Layer-by-Layer Particles Via DNA Hybridization. Small 2009, 5, 320-323.

40. Banchelli, M., Bombelli, F. B., Berti, D., Baglioni, P., and Nejat, D. Soft Hybrid Nanostructures Composed of Phospholipid Liposomes Decorated with Oligonucleotides. Meth. Enzymol. 2009, 464, 249-277.

41. Patolsky, F., Lichtenstein, A., and Willner, I. Amplified Microgravimetric Quartz-CrystalMicrobalance Assay of DNA Using Oligonucleotide-Functionalized Liposomes or Biotinylated Liposomes. J. Am. Chem. Soc. 1999, 122, 418-419.

42. Patolsky, F., Lichtenstein, A., and Willner, I. Electronic Transduction of DNA Sensing Processes on Surfaces: Amplification of DNA Detection and Analysis of Single-Base Mismatches by Tagged Liposomes. J. Am. Chem. Soc. 2001, 123, 5194-5205. 
43. Patolsky, F., Lichtenstein, A., and Willner, I. Electrochemical Transduction of LiposomeAmplified DNA Sensing. Angew. Chem., Int. Ed. 2000, 39, 940-943.

44. Chan, Y. H. M., van Lengerich, B., and Boxer, S. G. Lipid-Anchored DNA Mediates Vesicle Fusion as Observed by Lipid and Content Mixing. Biointerphases 2008, 3, FA17-FA21.

45. Thompson, M. P., Chien, M.-P., Ku, T.-H., Rush, A. M., and Gianneschi, N. C. Smart Lipids for Programmable Nanomaterials. Nano Lett. 2010, 10, 2690-2693.

46. Achalkumar, A. S., Bushby, R. J., and Evans, S. D. Cholesterol-Based Anchors and Tethers for Phospholipid Bilayers and for Model Biological Membranes. Soft Matter 2010, 6, 6036-6051.

47. Pfeiffer, I., and Hook, F. Bivalent Cholesterol-Based Coupling of Oligonucletides to Lipid Membrane Assemblies. J. Am. Chem. Soc. 2004, 126, 10224-10225.

48. Banchelli, M., Betti, F., Berti, D., Caminati, G., Bombelli, F. B., Brown, T., Wilhelmsson, L. M., Norden, B., and Baglioni, P. Phospholipid Membranes Decorated by Cholesterol-Based Oligonucleotides as Soft Hybrid Nanostructures. J. Phys. Chem. B 2008, 112, 10942-10952.

49. Erkan, Y., Halma, K., Czolkos, I., Jesorka, A., Dommersnes, P., Kumar, R., Brown, T., and Orwar, O. Controlled Release of Chol-Teg-DNA from Nano- and Micropatterned Su-8 Surfaces by a Spreading Lipid Film. Nano Lett. 2007, 8, 227-231.

50. Hurst, S. J., Lytton-Jean, A. K. R., and Mirkin, C. A. Maximizing DNA Loading on a Range of Gold Nanoparticle Sizes. Anal. Chem. 2006, 78, 8313-8318.

51. Bordi, F., and Cametti, C. Salt-Induced Aggregation in Cationic Liposome Aqueous Suspensions Resulting in Multi-Step Self-Assembling Complexes. Colloid. Surface. B. 2002, $26,341-350$.

52. Lytton-Jean, A. K. R., and Mirkin, C. A. A Thermodynamic Investigation into the Binding Properties of DNA Functionalized Gold Nanoparticle Probes and Molecular Fluorophore Probes. J. Am. Chem. Soc. 2005, 127, 12754-12755. 
53. Xu, J., and Craig, S. L. Thermodynamics of DNA Hybridization on Gold Nanoparticles. J. Am. Chem. Soc. 2005, 127, 13227-13231.

54. Hammond, K., Reboiras, M. D., Lyle, I. G., and Jones, M. N. Characterization of Phosphatidylcholine Phosphatidylinositol Sonicated Vesicles-Effects of Phospholipid Composition on Vesicle Size. Biochim. Biophys. Acta 1984, 774, 19-25.

55. Halling, K. K., Ramstedt, B., Nystrom, J. H., Slotte, J. P., and Nyholm, T. K. M. Cholesterol Interactions with Fluid-Phase Phospholipids: Effect on the Lateral Organization of the Bilayer. Biophys. J. 2008, 95, 3861-3871.

56. Hurst, S. J., Hill, H. D., and Mirkin, C. A. "Three-Dimensional Hybridization" With Polyvalent DNA-Gold Nanoparticle Conjugates. J. Am. Chem. Soc. 2008, 130, 12192-12200.

57. Lee, J. S., Stoeva, S. I., and Mirkin, C. A. DNA-Induced Size-Selective Separation of Mixtures of Gold Nanoparticles. J. Am. Chem. Soc. 2006, 128, 8899-8903.

58. Sun, Y., Harris, N. C., and Kiang, C. H. Phase Transition and Optical Properties of DNA-Gold Nanoparticle Assemblies. Plasmonics 2007, 2, 193-199.

59. Park, S. Y., and Stroud, D. Theory of Melting and the Optical Properties of Gold/DNA Nanocomposites. Phys. Rev. B 2003, 67.

60. Liu, J., and Lu, Y. Preparation of Aptamer-Linked Gold Nanoparticle Purple Aggregates for Colorimetric Sensing of Analytes. Nat. Protoc. 2006, 1, 246-252. 